Open Access

\title{
Smart devices employment in teaching and learning: reality and challenges in Jordan universities
}

\author{
Nouwar Q. Al-Hamad ${ }^{1}$, Asma Q. AlHamad ${ }^{2}$ and Faruq A. Al-Omari ${ }^{3^{*}}$ (D
}

\author{
* Correspondence: fomari@yu.edu.jo \\ ${ }^{3}$ Computer Engineering \\ Department, Yarmouk University, \\ Irbid, Jordan \\ Full list of author information is \\ available at the end of the article
}

\begin{abstract}
The aim of this study was to investigate the reality of smart devices' employment in teaching and learning in Jordanian universities from the perspective of instructors. A random sample of (364) instructors were targeted. A structured interview was used to collect data and qualitative analysis was performed to reveal results. Obtained results showed that (68.1\%) of respondents were against technology use specially inside the class, whereas (31.9\%) were in-favor. Although a high percentage were against technology use, yet most of them use the technology by some means. Distraction, misuse, and lack of skills were the most commonly reported drawbacks. On the other hand, enriched interaction and excitement were the main aspects encouraging instructors to employ the technology in the teaching process.
\end{abstract}

Keywords: Smart devices, Mobile learning, Education technology, E-learning

\section{Introduction}

The advents made in the broad field of information and communication technology (ICT), over the past two decades, has dramatically changed the means of interaction between individuals. In recent years, remarkable developments have been accomplished in devices, communication media, infrastructure, senders' and recipients' means, and protocols. If electricity was considered to be the most effectual invention at the rising edge of the twentieth century, it is believed that Internet is the most vital invention at the dawn of the twenty-first century. Many believed that Internet has changed the surface of earth for the good of mankind.

Human relations and interactions have been intensively influenced due to communication technologies and devices devoted for their own use in every aspect of life. One can notice the fast industrial and manufacturing developments made on the hardware technology, from personal computers (PCs) in the early 1980s to laptops. Then, leading to Interactive Personal Applications Devices (IPADS) and smart phones and smart devices during this last decade. Along with that, huge improvements in the communication media has been achieved. Along this line, developments were achieved from Co-Axial cables, that were limited in distance and capacity, to Fiber Optics to wireless communication. This altogether has reformed the classical communication system components consisting of sender, message, media, recipient, and protocol. In turn, 
individuals were able to reach knowledge, retrieve and restore information and employ data in less time and lesser effort.

Nowadays, smartphones and smart devices are in the hands of almost everyone worldwide. Young and old, females and males, rich and poor, all use these devices with almost no restrictions or boundaries. People use smart devices to communicate through voice calls, short and rich multimedia messaging, electronic mail, and many other ways. Communication is performed for entertainment, knowledge seeking, performing business transactions, and for other purposes. The World Wide Web represents a huge data warehouse and probably the biggest source of information. Moreover, practitioners start to exchange new emerging terminology that is associated with electronic interaction, like e-Government, e-Learning, e-Health, e-Commerce, and e-Banking. Further to that, terms like C2B (Customer to Business), B2B (Business to Business), C2G (Citizen to Government) and all the likes were born.

Education is not any far from this transformation. The emerging technology has dramatically changed the teaching and learning process and strategies, as well as the role of instructors and teachers. Both public education and higher education sectors were influenced. Smart devices together with Internet eased the effort and reduced time to get to information resources (Moreira, Ferreira, Santos, \& Durao, 2017; Yeap, Ramayah, \& Soto-Acosta, 2016). Technology enhanced the means to communicate and interact. Collaboration between learners and working groups became easier both for teachers and learners. The concept of distance learning became more renowned and evocative. Simulators and interactive platforms, virtual tools and laboratories, visual and audio applications, and electronic games are all examples of what technology offered for learners and teachers to enhance the teaching and learning environment (Wai, $\mathrm{Ng}$, Chiu, Ho, \& Lo, 2018; Xiangming \& Song, 2018).

Teachers can use their smart devices to upload course material via Learning Management Systems (LMS), place assignments and projects, follow up on students' progress, respond to students' concerns and remarks, place announcements, initiate discussion groups, and any other similar tasks to manage their classes. Besides these typical activities, students on the other side, can interact with each other and with their instructors in groups or individually, and they can refer to any supporting material inside or outside their learning environment (De Witt \& Gloerfeld, 2018; Navarro, Molina, \& Redondo, 2016). Some teachers encourage students to use smart devices outside classrooms, yet some are very reluctant to their use inside the classroom and during lectures. Despite of the many advantages of smart device's uses inside the classroom, several hindrances might prevent their use. Chief among these are: distraction, exploring undesirable web locations during class time, plagiarism, and exchange of unsolicited messages between students, as reported in some studies (Algoufi, 2016; Anshari, Almunawar, Shahrill, Wicaksono, \& Huda, 2017; Joo, Kim, \& Kim, 2016; Remon, Sebastián, Romero, \& Arauzo, 2017).

The aim of this study was to investigate the instructors' perceptions of employing smart devices in the teaching and learning process in Jordanian universities located in the north region of the country. To this end, the attitude of instructors towards the use smart devices in the teaching and learning process is a typical application of Technology Acceptance Model (TAM), which was first developed by Davis (1989).

The rest of the paper is organized as follows: the next section gives a brief background of the e-learning environment in Jordanian universities. Then a section describing the 
theoretical framework for the study. After that, a literature survey section is provided presenting related previous studies in the field. Then a methodology section is provided, followed by the results and discussion section. Finally, concluding remarks and recommendations are provided.

\section{Background}

Jordan has invested a lot in the technology infrastructure in all sectors over the last two decades. Many initiatives were adopted to intensify and magnify the employment of technology. "Connecting Jordanians" initiative was launched in (2003) in an aim to coordinate and accelerate critical developments and reforms intended to make ICT an important facet in the lives of all Jordanians and to improve their economic, social and cultural prospects in meaningful ways. In the light of this initiative, Jordanian Universities Network (JUNet) was established in (2003) as a private non-profit organization owned by Jordanian public universities in an aim to serve public and private universities in Jordan through shared ICT services framework model and to elevate the employment of technology in higher education at all levels.

In this sense, JUNet, as a firm, doesn't have the power to enforce a policy on member universities, but it can propose strategies, pursue awareness, and establish culture though workshops and training. JUNet can take action only if stakeholders adopt a strategy. To this end, the reality and challenges of using smart devices in Jordanian higher education sector is still unclear unless investigated. Although, the topic has been extensively addressed by researchers worldwide, yet no studies scrutinized that in Jordan. There is no doubt that results and findings from similar studies in other countries can be referenced and used as a guide by decision makers. But, each community has its own specificity, values and peculiar standards. Therefore, authors strongly believe in the genuine need to investigate the attitudes of practitioners whether instructors or students towards the acceptance of technology in the teaching and learning process, and the need to study the reality of the employment of smart devices in teaching and learning in Jordanian universities and the challenges facing that.

\section{Theoretical framework}

Technology Acceptance Model (TAM) was first created by Davis (1989), based on the theory of reasoned action (TRA) by Fishbein and Ajzen (1975) in psychology research. The TRA postulates that individual's behavior is driven by behavioral intention where behavioral intention is a function of an individual's attitude toward the behavior and subjective norms surrounding the performance of the behavior. Therefore, according to TRA, behavior is a function of attitudes and beliefs.

Davis (1989) proposed that perceived ease of use and perceived usefulness of technology are predictors of user attitude towards using the technology, subsequent behavioral intentions and actual usage. Perceived ease of use was also considered to influence perceived usefulness of technology. This proposed model was called Technology Acceptance Model (TAM). The original TAM is presented in Fig. 1 (Davis, 1989).

According to TAM, perceived usefulness refers to the degree to which the user believes that using the technology improves user's work performance. While perceived ease of use refers to how effortless the user perceives using the technology will be. Both are considered distinct factors influencing the user's attitude towards using the technology. 


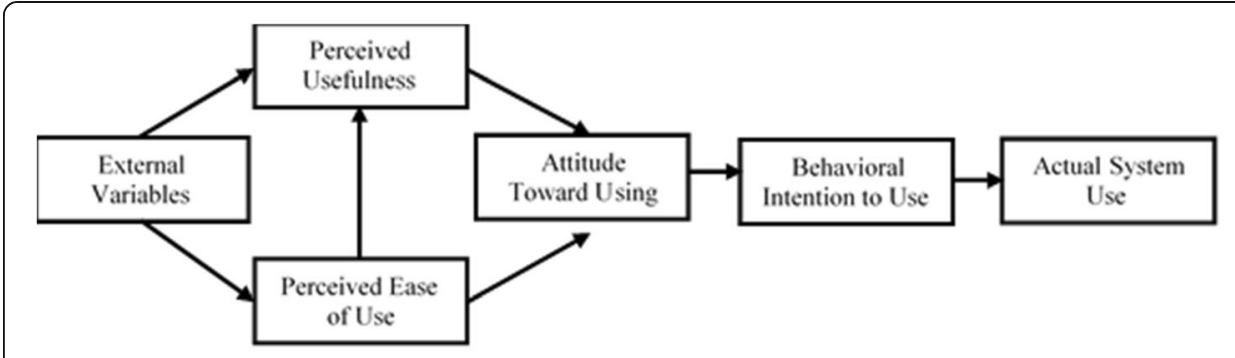

Fig. 1 Original technology acceptance model (TAM) by Davis (1989)

However, perceived ease of use is also hypothesized to influence perceived usefulness and attitude towards using the technology. Such attitude towards using the technology determines the behavioral intention to use that technology.

This model has been applied in numerous studies exploring user acceptance of information technology, for example, e-mail (Szajna, 1996), web browser (Morris \& Dillon, 1997), telemedicine (Hu, Chau, Sheng, \& Tam, 1999), e-collaboration (Dasgupta, Granger, \& Mcgarry, 2002), blackboard (Landry, Griffith, \& Hartman, 2006), and e-learning (Al-Adwan, AlAdwan, \& Smedley, 2013).

In 2007, Masrom proposed a modification on the original TAM. In the modified model, the e-learning was considered a system that makes use of Internet and web technology in accomplishing its mission of delivering information to and interacting with the students through a computer interface (Masrom, 2007). The modified TAM is a reduced model, excluding actual system use, and the external variables as there was no immediate intention to examine antecedents to perceived usefulness and perceived ease of use, as shown in Fig. 2.

According to the modified model, five research hypotheses were proposed based on the diagram of the TAM model in the context of the e-learning system; namely H1 to H5.

Several other studies have tackled the acceptance of technology in e-learning and proposed modification of the TAM model. Addressed the TAM model and suggested modifications. An example is the study carried out by Liu, Liao, and Pratt (2009). According to their proposal, an integrated theoretical framework to study users' acceptance for e-learning was suggested that was based on the technology acceptance model, flow theory and media richness theory.

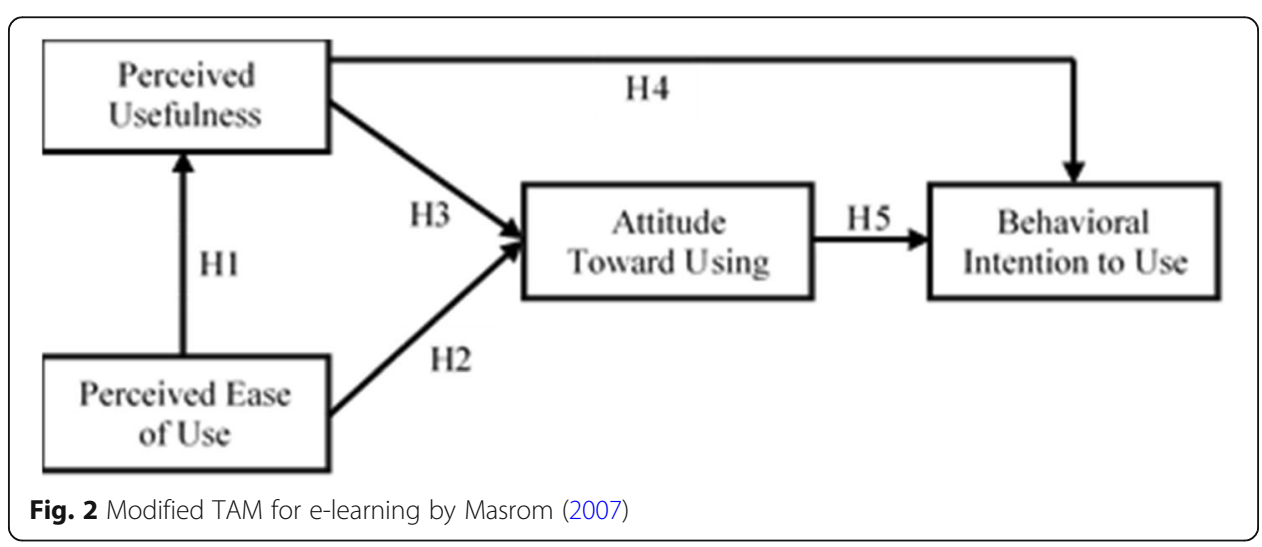


This study utilizes the technology acceptance model to perceive the instructors' attitudes as well as actual reality of using mobile phones and smart devices in the teaching and learning process in Jordanian universities.

\section{Literature review}

Several studies have been conducted in recent years that addressed the use of mobile phones and smart devices in the teaching and learning process. The subject has been tackled from different aspects and perspectives.

In 2012, Mtega, Bernard, Msungu, and Sanare (2012) conducted a study to investigate how mobile phones were facilitated in the teaching and learning process. Authors assessed the common limitations of m-learning at Sokoine University of Agriculture, Tanzania. Interviews, observations and a questionnaire were used for data collection. Thirty teaching staff and 40 students were randomly selected and included in the study. It was found that few respondents had smart phones with a number of m-learning applications most of them being teaching staff. The study reported that $42 \%$ of targeted staff use smart mobiles to share information resources with students. Whereas only $7.5 \%$ of targeted students use their mobiles to download study material. Among the reported constraints on mobile usage was unawareness of teaching staff of the capabilities of their mobile phones such that they underutilized them. In addition, cost associated with downloading multimedia content was the main constraint facing students from using phones for learning purposes.

In 2014, Paz-Albo Prieto (2014) carried out a study in Rey Juan Carlos University, Spain. The aim was to explore the perceptions of students on the use of Socrative as a Student Response System (SRS) via mobile phones. Socrative was a means to increase interactivity inside the classroom. A questionnaire based survey was conducted to inquire into students' perceptions on their use. Data was collected from 70 randomly selected students. Results revealed that Socrative can much better engage students in the learning process, promoting collaboration and encouraging participation. However, some problems related to the use of SRSs were revealed such as the off-task use of the smartphones in the classroom.

In 2015, Santamarta et al. (2015) conducted a study in three Spanish universities aimed to highlight the enormous potential of using tablet PCs in a classroom environment as an educational resource. Participating universities believed that versatility, portability and functionality of tablets made them very suitable to support teaching in engineering degrees and masters and could have impact on the training process. Authors reported that the use of technology in classrooms in Spanish universities was following an upward path. In many cases, technological devices were substituting other materials that until that time were being used, such as books, and notebooks. Authors concluded that to fully integrate tablets in university curricula, it is necessary for teachers to have basic technological and pedagogical training in their use. Furthermore, authors emphasized that tablets must be used with a clear purpose, to achieve specific objectives in official programs of educational institutions. Authors believed that tablets, by themselves, are not an asset to education; rather they are instruments that help to change and modify methodologies in the classroom. They enable immediate presentation of information; multimedia and interactive information; the connection between the learning environment and reality; implementation of cooperative activities and the 
development of cognitive skills. They also allow students to acquire digital skills in the classroom, and integrate students into the future of learning, where they can exchange their teachers and traditional methodologies for technical resources that enhance motivation and learning.

In 2016, Al-Emran, Elsherif, and Shaalan (2016) investigated attitudes towards the use of mobile learning in higher education both in Oman and United Arab Emirates. In their study, authors explored students and educators' attitudes towards the use of Mlearning in higher educational universities within five universities in both neighboring countries in the Arab Gulf region. Two survey questionnaires were conducted for students and educators to collect data. The participants of the study were 383 students and 54 instructors. To investigate students and educators attitudes, several factors pertaining to students and educators were examined. As per students, factors like gender, age, country, level of study, smartphone ownership, and major were examined. Whereas for educators, factors like age, country, academic rank, academic experience and smartphone ownership were studied. Findings indicated significant differences among students' attitudes towards M-learning with regard to their smartphone ownership, country and age. Furthermore, results revealed that M-learning was a promising pedagogical technology that could be employed in the higher educational environments within the Arab Gulf countries.

In 2017, Heflin, Shewmaker, and Nguyen (2017) conducted a study to explore the impact of mobile technology on student attitudes, engagement, and learning in Abilene Christian University, USA. Authors evaluated student learning in three different collaborative learning environments, both with and without mobile technology. The aim was to assess students' engagement, critical thinking, and attitudes toward collaborative learning. The results revealed that mobile technology is associated with positive student perceptions of collaborative learning but with increased disengagement by students during class. Furthermore, results indicated that the level of students' critical thinking was more closely associated with the tools used to construct written responses than with the collaborative learning environment style. Students constructing paragraph responses on a mobile device demonstrated significantly less critical thinking than those who used a computer keyboard or wrote responses by hand.

In 2017, Anshari et al. (2017) performed a study on whether embracing smartphones in classroom teaching enhances the learning or perhaps an interference. The study was carried out through a survey and interview/discussion with a focus group of students. Authors found that students use their smartphones to access teaching materials or supporting information, or as learning aids. For as, these devices provide convenience, portability, comprehensive learning experiences, multi sources and multitasks, and environmentally friendly. They also use smartphones to interact with teachers outside classes and to manage their group assignments. Authors however, alleged that integrating smartphones in a classroom-teaching environment is a challenging task. Some of the challenges are distraction, dependency, lacking hands on skills, and the reduce quality of face-to-face interaction. To avoid any disturbances in using smartphones within a classroom environment, they suggested that proper rules of using smartphones in class should be established before teaching, and students need to abide to these rules.

In 2017, Alwraikat (2017) carried out a study to investigate obstacles hindering graduate students use of smartphones in their learning at the University of Jordan. The 
study used a questionnaire to collect data from 108 randomly selected graduate students. Author reported some obstacles facing students from their own perspective. Chief among these are university regulations that prevent in class use of smart phones, cost, awareness of importance of technology, and limited wireless network infrastructure on campus.

Several other studies tackled this topic from different perspectives. A number of these studies focused on the advantages and disadvantages of using smart devices in the teaching and learning process. While others focused on the obstacles and challenges facing the use of this technology whether inside or outside the classroom (Moreira et al., 2017; Navarro et al., 2016; Remon et al., 2017; Yeap et al., 2016).

\section{Methodology}

\section{Population and sample}

The study population consisted of all instructors in the seven universities located in the north region of Jordan. There were close to (3000) instructors working in these universities, according to the Jordanian Ministry of Higher Education (MoHE) statistics. A random sample of (600) instructors were targeted to collect data.

\section{Data collection}

authors used a structured interview to collect data. The interview consisted primarily of two main questions, with several subsequent minor questions. The first question aimed at revealing the attitude of instructors toward the use of technology (smart devices like mobile phones or tablets) in the teaching and learning process. The question stated "Are you in favor of employing smart devices in the teaching process inside or outside the classroom? and Why?". The second question aimed at revealing the actual technology usage. It stated "Do you use/allow your students to use smart devices inside or outside the classroom for teaching and learning purposes? and How?"

\section{Data analysis and processing}

To achieve the goals of the study, authors employed the quantifying qualitative methodology to analyze the collected data. Quantifying qualitative approach refers to the process of categorizing verbal or behavioral data to classify, summarize and tabulate that data. Thus, this process involves turning the data from words into numbers. This implicates three main steps, namely: developing and applying codes, then identifying themes, patterns and relationships, and finally summarizing, representing and interpreting the data (Chi, 1997). In the first step, data from respondents were organized into groups resembling ideas based on the interview question. Then data was carefully read and a category system was constructed that allows all of the data to be categorized systematically. Accordingly, the categories were internally homogeneous and externally heterogeneous. Lastly, summarization, representation and interpretation was performed in terms of the frequency of occurrence and percentages of each idea included in the question.

This process was employed in this study. Authors have identified the main concerns, obstacles and challenges facing the use of smart devices in teaching as reported in the literature presented in the Literature review section as well as their prior knowledge of the use of technology in Jordanian universities. These concerns were considered the 
distinct and independent themes and categories to classify responses. Then, authors used these classes as a base to classify responses.

Responses from instructors were numbered for referencing purposes. The classification process was performed in three steps. In the first step, every author carried out the classification independently and the classification results were recorded. Then, this process was repeated after 1 month on all responses by all three authors independently. To this end, six classification scores were recorded. The goal behind these two steps were to eliminate the inter- and intra-observer variations. In the final step, a panel by all three authors was held to review the results. The classification for every response was reviewed. When there was a match in classification, the case was closed. When a difference in classification was encountered, the case was opened from discussion until a consensus was reached.

\section{Results and discussion}

A random sample of (600) instructors from the seven universities in the north region of Jordan were targeted. The interview questions were hosted in the Google Drive and targeted instructors were informed through email with a link to the interview. Detailed information on the procedure and steps of participating in the study were furnished. Several follow up email messages and gentle reminders were sent to guarantee the highest possible engagement. A total of (421) responses were received within the preset deadline. When responses thoroughly investigated, it was found out that (364) responses were complete. Whereas, the remaining (57) responses were either incomplete or corrupted, and were consequently discarded. Data collected from the (364) complete responses was then statistically analyzed utilizing quantifying qualitative approach. Table 1 shows the demographic distribution of respondents based on their field of study. To this end, the actual size of the sample used in the analysis was performed on (61\%) of the targeted sample size and a little over $(12.13 \%)$ of the study population.

Qualitative analysis was conducted on the collected data to reveal results. In response to first main question of the interview, which stated "Are you in favor of employing smart devices in the teaching process inside or outside the classroom? and Why?", it was found out that (248) instructors were against the use of smart devices in the teaching and learning process, which comprises (68.1\%) of respondents. Whereas, (116) instructors were in favor of their use, which represents (31.9\%) of the respondents. These results are shown in Fig. 3.

Table 1 Demographic distribution of respondents based on field of study

\begin{tabular}{lll}
\hline Field of Study & Number of Instructors & Percentage \\
\hline Engineering \& ICT & 73 & $20.06 \%$ \\
Health \& Welfare & 64 & $17.58 \%$ \\
Arts and Humanities & 52 & $14.29 \%$ \\
Education & 49 & $13.46 \%$ \\
Natural Sciences & 44 & $12.09 \%$ \\
Social Sciences & 39 & $10.71 \%$ \\
Business \& Law & 37 & $10.16 \%$ \\
Agriculture \& Veterinary & 6 & $1.65 \%$ \\
Total & 364 & $100 \%$ \\
\hline
\end{tabular}




\section{"Are You In Favor of Employing Smart Devices in The Teaching Process Inside or Outside The Classroom?"}

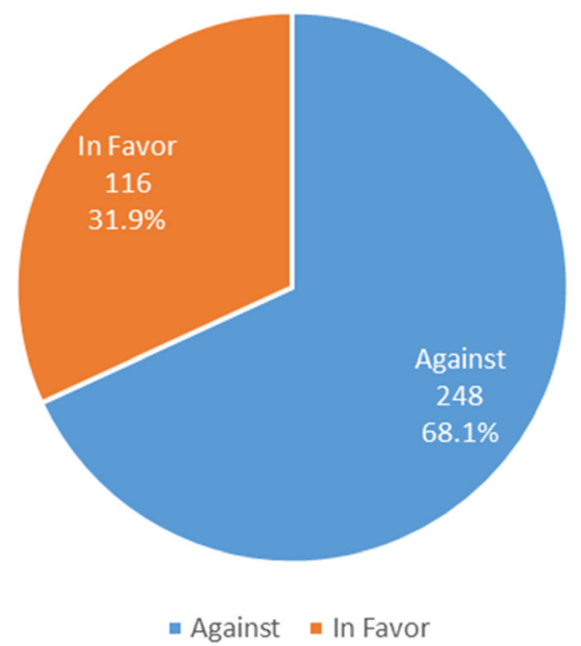

Fig. 3 Instructors' perceptions on the use of smart devices in the teaching and learning process

The percentage of instructors against the employment of smart devices was astonishingly high. When investigating reasons behind instructors' stands (Why?), several explanations were provided. Quantification of qualitative data methods were used to draw results. First, the responses were organized into two main groups, namely against group (group 1) consisting of 248 responses and in-favor group (group 2) consisting of 116 responses, for a total of 364 responses. Then, classification was systematically performed according to the three-step process described in the Methodology section. Finally, the number of occurrences in every category was computed and a percentage of the total number of occurrences was calculated.

The most common obstacles and difficulties reported in instructors' responses were that they believed they can't control the classroom in the presence of such devices in the hands of students, and causes a lot of distraction. Worse yet, some believed that this technology ruins the future of education. According to their responses, they commented that new generations of students will be spoiled, distracted, and impossible to control especially inside classrooms. Other reasons were also reported like; these devices do not, according to them, help achieve the goals of the lecture and that the lecture itself is sufficient. Others just don't believe in engaging this new technology and that it is useless on the whole teaching and learning process without any justification. These results were tabulated in Table 2 with percentages of occurrences in the responses.

In response to the interview second question stated "Do you use/allow your students to use smart devices inside or outside the classroom for teaching and learning purposes? and How?", different responses were reported. Investigating responses gathered from instructors of group 1, i.e. those who were against the use of smart devices as revealed in the first question, it was interestingly found out that (149) instructors out of (248) of this group that is $(60.1 \%)$ conveyed that they employ smartphones inside and outside classrooms extensively. They claimed that the nature of the courses they teach requires 
Table 2 Obstacles/difficulties facing the use of smart devices as reported by instructors and the number of occurrences

\begin{tabular}{llll}
\hline Obstacle/Difficulty & Group & No. of Instructors & Percentage within Group \\
\hline Distraction & Group 1 & 193 & $77.82 \%$ \\
& Group 2 & 61 & $52.59 \%$ \\
& Total & 254 & $69.78 \%$ \\
Misuse & Group 1 & 191 & $77.02 \%$ \\
& Group 2 & 57 & $49.14 \%$ \\
& Total & 248 & $68.13 \%$ \\
Difficulties in controlling classroom & Group 1 & 180 & $72.58 \%$ \\
& Group 2 & 58 & $50.00 \%$ \\
& Total & 238 & $65.38 \%$ \\
Devices don't help achieving class objectives & Group 1 & 98 & $39.52 \%$ \\
& Group 2 & 9 & $7.76 \%$ \\
& Total & 107 & $29.40 \%$ \\
Technology spoils generations & Group 1 & 36 & $14.52 \%$ \\
& Group 2 & 8 & $6.90 \%$ \\
& Total & 44 & $12.09 \%$ \\
Lack of skills & Group 1 & 40 & $16.13 \%$ \\
& Group 2 & 23 & $19.83 \%$ \\
& Total & 63 & $17.31 \%$ \\
& Group 1 & 107 & $43.15 \%$ \\
& Group 2 & 49 & $42.24 \%$ \\
& Total & 156 & $42.86 \%$ \\
\hline
\end{tabular}

this technology. Examples of applications and activities they use were like virtual simulators, virtual laboratories, calculators and convertors. In addition, those instructors reported that they use smart devices for basic purposes like uploading teaching and supporting material and other basic routine activities of students follow up. Even though, they were still skeptical to the engagement of this technology.

Further to this, results indicated that (75) instructors out of those (248) against (i.e. $30.2 \%$ ), in fact use smartphones or tablets in some basic activities. They reported that they use technology to manage their academic websites and courses' homepages on the university learning management system (LMS), and to upload courses syllabi, as their universities oblige them to do so as a minimum.

Finally, the remaining (24) instructors in this group (i.e. 9.7\%) reported that they don't engage this technology in their classes as they strongly believe it is a waste of time and effort. Worse yet, they believe that this technology ruins the future of education. According to their responses, they commented that new generations of students will be spoiled, distracted, and impossible to control especially inside classrooms. These results were portrayed and summarized in Fig. 4.

Investigating the results revealed from the respondents in favor of engaging smart devices in the teaching and learning process (group 2) demonstrated that (26) instructors out of (116) that is (22.4\%) employ smart devices extensively in almost all class activities. They expressed eagerness to technology use wherever possible. Those instructors revealed that they use their own devices outside the classroom to access the Learning 


\section{Group 1: Against Using Smart Devices}

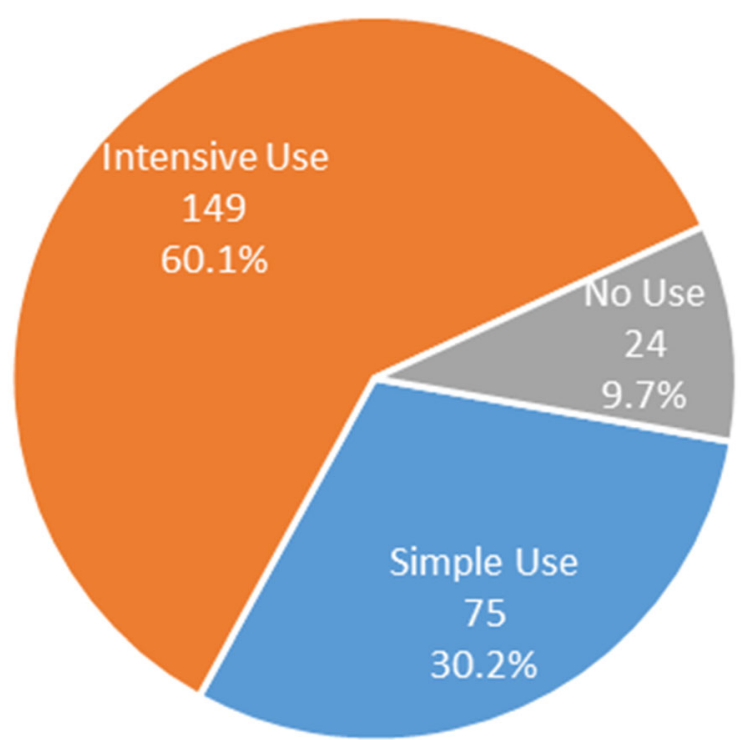

Fig. 4 Classification of instructors against the use of smart devices

Management System (LMS) adopted by their universities to upload courses' syllabi, teaching and supporting material, assignments, projects, and other course related material. They further reported that they encourage their students to utilize available chatting forums and establish discussion groups with instructor and between students themselves. In addition, some of those respondents mentioned that they direct their students, at times, to seek best practices and demonstrations available on the worldwide web like educational YouTube and other similar platforms. In class, those instructors revealed in their responses that they try to use their own smart devices in front of students in every activity possible. In addition to that, they mentioned that they portray the course material on LMS via their devices. Furthermore, they reported that they sometimes show their students some demonstrations and illustrative videos via their devices. As mentioned in some responses, they not only encourage but rather request their students to use their own smartphones or tablets to participate in some exercises or illustrations that use virtual simulators or laboratories, or in some cases online calculators and data converters. Further to this, some respondents revealed that they interact with their students via social media applications like Facebook ${ }^{\circ}$, WhatsApp ${ }^{\circ}$, and the likes. The idea behind it was, as some respondents reported, to enhance collaboration and interaction.

Nevertheless, (61) respondents (i.e. 52.6\%) of this group reported that they tend to use smart devices and encourage their students too for basic activities mostly outside the classroom. In class, they tend to use their devices occasionally when there is an actual need. Though, they were hesitant to allow students to use smart devices, because of distraction and misuse as they claimed. According to this subgroup, smart devices' uses were centered around the LMS related activities like uploading and retrieving course material, syllabi, supporting material, assignments, announcements, etc. They 


\section{Group 2: In Favor of Using Smart Devices}

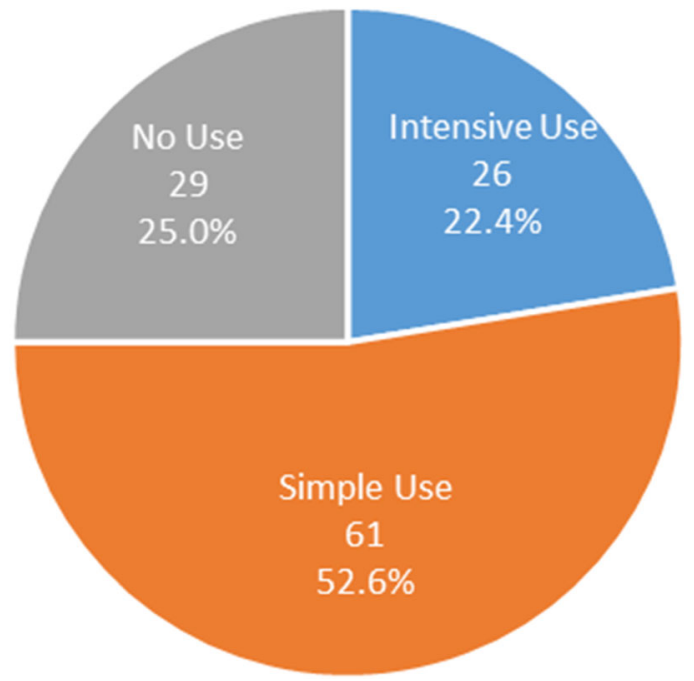

Fig. 5 Classification of instructors in favor of using smart devices

also conveyed that they tend to use smart devices to follow up students' access times and progression on the LMS. They reported that they follow up on their students so they can focus on those who don't access the LMS regularly and try to help them make better progress in the course due.

Finally, (29) of respondents in this group, that is $(25.0 \%)$, revealed that although they are in favor of using technology, they don't actually employ it in their teaching strategies. Different reasons were mentioned, like lack of required skills, and reluctance due to misuse or distraction. When asked why in favor of this technology use, some expressed they anticipate it allows better utilization of class time, and that they were adored by other countries experiences and accomplishments in this regard. Some said they hope the day would come in Jordan where this strategy is adopted as they believe this technology goes in harmony with attitudes and tempers of new generations of students. Figure 5 depicts the obtained results.

When merging the responses from both groups, who were in favor and against engagement of smart devices in teaching, it was found out that percentages of instructors' usage of technology in teaching and learning are as shown in Table 3 according to engagement level.

On the other hand, when investigating instructors' responses with regard to allowing and/or encouraging students to utilize this technology inside and outside classroom, the results are as shown Table 4.

Table 3 Level of smart devices use by instructors themselves whether inside or outside classroom

\begin{tabular}{lll}
\hline Level of Smart Devices Use By Instructors & Number of Instructors & Percentage \\
\hline Intensive Use & 175 & $48.08 \%$ \\
Simple Use & 136 & $37.36 \%$ \\
No Use & 53 & $14.56 \%$ \\
Total & 364 & $100 \%$ \\
\hline
\end{tabular}


Table 4 Level of smart devices use by students

\begin{tabular}{lll}
\hline Level of Smart Devices Use By Students & In Class & Outside Class \\
\hline Intensive Use & $26(7.14 \%)$ & $311(85.44 \%)$ \\
Simple Use & $110(30.22 \%)$ & $29(7.97 \%)$ \\
No Use & $228(62.64 \%)$ & $24(6.59 \%)$ \\
Total & $364(100 \%)$ & $364(100 \%)$ \\
\hline
\end{tabular}

Finally, Table 5 portrays the most commonly used applications instructors use in the teaching and learning process as the respondents replied.

These results agree to a great extend with the results of most studies addressed the topic (Alwraikat, 2017; Anshari et al., 2017; Mtega et al., 2012; Paz-Albo Prieto, 2014; Santamarta et al., 2015). For those who were in favor of incorporating technology in teaching and learning, they perceived that the role of instructors has changed and this technology was no more a luxury, rather it is a must just like notebooks and pencils. They believed the technology is the future of generations. For those who were against, distraction and misuse were the main constraints, especially inside the classroom. Furthermore, the reported results agree to great extent with the relationships between "Perceived Usefulness" and "Attitude Towards Using", "Perceived Ease of Use" and "Attitude Towards Using", as well as between "Attitude Towards Using" and "Behavioral Intention to Use" in the TAM model of Davis (1989) and the modified TAM for e-learning by Masrom (2007).

\section{Conclusions}

In this study, the reality of using smart devices in the teaching and learning process in Jordanian universities was investigated from the perspective of instructors. Further, the challenges and obstacles facing their use was explored, as seen by instructors themselves. In the light of the obtained results, it was obvious that there is still a lack of culture among instructors on the importance of engaging technology in education. Hesitation primarily came from either lack of required

Table $\mathbf{5}$ Top applications used for teaching and learning purposes

\begin{tabular}{ll}
\hline Application & Usage (\%) \\
\hline LMS & $93.41 \%$ \\
E-Mail & $94.78 \%$ \\
Whats App & $92.58 \%$ \\
Facebook & $87.36 \%$ \\
Youtube & $20.33 \%$ \\
Search Engines (like google) & $89.01 \%$ \\
Wikis & $9.62 \%$ \\
Skype & $32.42 \%$ \\
Online Claculators/Convertors, & $10.16 \%$ \\
virtual Laboratories & \\
Others & $13.19 \%$ \\
\hline
\end{tabular}


skills, or reluctance due misuse and distraction inside classroom. Regulations governing the use of technology were unclear. Therefore, an effort should be placed in this regard from the Ministry of Higher Education in Jordan and the universities themselves. Further to that, awareness and dusting skills training is highly recommended as part of the orientation programs of newly hired faculty members and continuing education programs.

\section{Acknowledgements}

All authors read and approved the final manuscript.

\section{Authors' contributions}

NQA was the principal investigator in this study. She suggested addressing the topic, stated the goals and adjectives of the study. Further to this, she together with FAA finalized the main questions of the interview. As for the write-up of the manuscript, she was responsible for the major portion of the introduction, background, literature review. In addition to that she was responsible for discussing the obtained results. AQA was responsible for enriching the introduction with the ICT background of the introduction, posting the interview on Goggle Drive and following up with targeted instructors to collect the data. Together with FAA, she was responsible for the technical and statistical data analysis (quantifying qualitative data analysis) by screening the responses, setting up categories and codes, and then performing the quantification process. Obtained results were the fruits of her efforts together with FAA. FAA was responsible for setting up objectives and goals together with NQA and linking that with the interview questions. His core role was to carry out the fine details of statistical analysis and obtaining the reported results, and linking the results to the study objectives with the help of NQA. He was responsible through his connections for facilitating the data collection process. The manuscript compilation and finalization was his responsibility. He serves as the corresponding author, and will be responsible for keeping track with the journal through the submission, reviewing, and hopefully revision process once the manuscript has the chance to be accepted. All authors read and approved the final manuscript.

Funding

Authors declare that no funding for the research was provided from any side.

\section{Availability of data and materials}

The datasets collected and analyzed during the current study are not publicly available due [To the fact that the interview questions were stated in Arabic language (mother tongue of instructors). The majority of tragted instructors use Arabic language even in teaching. So it was hard to address them with questions stated in English. Furthermore, we noticed that a good number of respondents filled the form using hand writing, and made a scanned copy of their responses and posted them on Google Drive as directed. In addition, we carried out all the analysis including the quantification of qualitative data in Arabic as we were thinking of sending the manuscript to an Arabic journal. For these reasons, all collected data and compiled data in the analysis were in Arabic and we think is hard to make them available in a meaningful form to journal readers].

However, the corresponding author is ready to furnish samples of these responses on reasonable request.

\section{Competing interests}

The authors declare that they have no competing interests.

\section{Author details}

${ }^{1}$ Department of Administration and Education Foundations, Yarmouk University, Irbid, Jordan. ${ }^{2}$ Librarian and Information Department, Imam Abdulrahman Bin Faisal University, Dammam, Saudi Arabia. ${ }^{3}$ Computer Engineering Department, Yarmouk University, Irbid, Jordan.

Received: 13 October 2019 Accepted: 27 January 2020

Published online: 03 February 2020

\section{References}

Al-Adwan, A., AlAdwan, A., \& Smedley, J. (2013). Exploring students' acceptance of e-learning using technology acceptance model in Jordanian universities. International Journal of Education and Development using Information and Communication Technology (IJEDICT), 9(2), 4-18.

Al-Emran, M., Elsherif, H., \& Shaalan, K. (2016). Investigating attitudes towards the use of mobile learning in higher education. Computers in Human Behavior, 56, 93-102.

Algoufi, R. (2016). Using tablet on education. World Journal of Education, 6(3), 113-119.

Alwraikat, M. (2017). Smartphones as a new paradigm in higher education overcoming obstacles. International Journal of Interactive Mobile Technologies, 11(4), 114-135.

Anshari, M., Almunawar, M. N., Shahrill, M., Wicaksono, D. K., \& Huda, M. (2017). Smartphones usage in the classrooms: Learning aid or interference? Education and Information Technologies, 22, 3063-3079.

Chi, M. T. H. (1997). Quantifying qualitative analyses of verbal data: A practical guide. Journal of the Learning Sciences, 6(3), $271-315$.

Dasgupta, S., Granger, M., \& Mcgarry, N. (2002). User acceptance of e-collaboration technology: An extension of the technology acceptance model. Group Decision and Negotiation, 11, 87-100. 
Davis, F. D. (1989). Perceived usefulness, perceived ease of use and user acceptance of information technology. MIS Quarterly, 13(3), 319-339.

de Witt, C., \& Gloerfeld, C. (2018). Mobile learning and higher education. In D. Kergel, B. Heidkamp, P. Telléus, T. Rachwal, \& S. Nowakowski (Eds.), The digital turn in higher education. Wiesbaden: Springer VS.

Fishbein, M., \& Ajzen, I. (1975). Belief, attitude, intention and behavior: An introduction to theory and research. Reading: AddisonWesley.

Heflin, H., Shewmaker, J., \& Nguyen, J. (2017). Impact of mobile technology on student attitudes, engagement, and learning. Computers \& Education, 107, 91-99.

Hu, P. J., Chau, P. Y. K., Sheng, O. R. L., \& Tam, K. Y. (1999). Examining the technology acceptance model using physical acceptance of telemedicine technology. Journal of Management Information Systems, 16(2), 91-112.

Joo, Y. J., Kim, N., \& Kim, N. H. (2016). Factors predicting online university students' use of a mobile learning management system (m-LMS). Educational Technology Research and Development, 64(4), 611-630.

Landry, B. J. L., Griffith, R., \& Hartman, S. (2006). Measuring student perceptions of blackboard using the technology acceptance model. Decision Sciences, 4(1), 87-99.

Liu, S.-H., Liao, H.-L., \& Pratt, J. A. (2009). Impact of media richness and flow on e-learning technology acceptance. Computers \& Education, 52, 599-607.

Masrom, M. (2007). Technology acceptance model and e-learning. In Proc. of 12th International Conference on Education, Sultan Hassanal Bolkiah Institute of Education Universiti Brunei Darussalam, 21-24 May 2007.

Moreira, F., Ferreira, M. J., Santos, C. P., \& Durao, N. (2017). Evolution and use of mobile devices in higher education: A case study in Portuguese higher education institutions between 2009/2010 and 2014/2015. Telematics and Informatics, 34(6), 838-852.

Morris, M. G., \& Dillon, A. (1997). The influence of user perceptions on software utilization: Application and evaluation of a theoretical model of technology acceptance. IEEE Software, 14(4), 56-75.

Mtega, W. P., Bernard, R., Msungu, A. C., \& Sanare, R. (2012). Using mobile phones for teaching and learning purposes in higher learning institutions: The case of Sokoine University of Agriculture in Tanzania. In 5 th UbuntuNet Alliance Annual Conference (Vol. 2012, pp. 118-129). Dares Salaam: UbuntuNet Alliance.

Navarro, C. X., Molina, A. I., \& Redondo, M. A. (2016). Factors influencing students' acceptance in m-learning: A literature review and proposal of a taxonomy. In $18^{\text {th }}$ International Symposium on Computers in Education (SIIE), University Salamanca, Sep 13-16, 2016 (pp. 1-6).

Paz-Albo Prieto, J. (2014). The impact of using smartphones as student response systems on prospective teacher education training: A case study. El Guiniguada Revista de investigaciones y experiencias en Ciencias de la Educación, 23, 125-133.

Remon, J., Sebastián, V., Romero, E., \& Arauzo, J. (2017). Effect of using smartphones as clickers and tablets as digital whiteboards on students' engagement and learning. Active Learning in Higher Education, 18(2), 173-187.

Santamarta, J. C., Hernández-Gutiérrez, L. E., Tomás, R., Cano, M., Rodríguez-Martíne, J., \& Arraiza, M. P. (2015). Use of tablet PCs in higher education: A new strategy for training engineers in European bachelors and masters programmes. Procedia Social and Behavioral Sciences, 191, 2753-2757.

Szajna, B. (1996). Empirical evaluation of the revised technology acceptance model. Management Science, 42(1), 85-92

Wai, I. S. H., Ng, S. S. Y., Chiu, D. K. W., Ho, K. K. W., \& Lo, P. (2018). Exploring undergraduate students' usage pattern of mobile apps for education. Journal of Librarianship and Information Science, 50(1), 34-47.

Xiangming, L., \& Song, S. (2018). Mobile technology affordance and its social implications: A case of "rain classroom". British Journal of Educational Technology, 49(2), 276-291.

Yeap, J., Ramayah, T., \& Soto-Acosta. (2016). Factors propelling the adoption of m-learning among students in higher education. Electronic Markets, 26(4), 323-338.

\section{Publisher's Note}

Springer Nature remains neutral with regard to jurisdictional claims in published maps and institutional affiliations.

\section{Submit your manuscript to a SpringerOpen ${ }^{\circ}$ journal and benefit from:}

- Convenient online submission

- Rigorous peer review

- Open access: articles freely available online

- High visibility within the field

- Retaining the copyright to your article

Submit your next manuscript at $\boldsymbol{\nabla}$ springeropen.com 